\title{
Incidence and outcome of severe ante- partum hemorrhage at the Teaching Hospital Yalgado Ouédraogo in Burkina Faso
}

Martin Lankoande ${ }^{1^{*}}$, Papougnezambo Bonkoungou², Sosthène Ouandaogo ${ }^{3}$, Marcelin Dayamba², Ali Ouedraogo ${ }^{2}$, Francis Veyckmans ${ }^{4}$ and Nazinigouba Ouédraogo ${ }^{2}$

\begin{abstract}
Background: Hemorrhage is the main cause of maternal death during pregnancy. This study aims to evaluate incidence and outcomes of Severe Ante Partum Hemorrhage (SAPH) during the third trimester of pregnancy prior to delivery.

Methods: Analytical cross-sectional study with prospective data collection during 12 months in Yalgado Ouedraogo Hospital, Ouagadougou, Burkina Faso. In this context SAPH is specifically referring to Ante Partum Hemorrhage (APH) and Intra Partum Hemorrhage (IPH) in the 3rd trimester. Postpartum Hemorrhage (PPH) was not included.

Results: During our study 7,469 women were admitted in obstetrics and 122 cases of SAPH were recorded. SAPH represented $1.6 \%(n=122)$ of hospitalizations causes and $14.5 \%(n=1083)$ of hemorrhages during pregnancy. Mean age was $27.8 \pm 6.9$ years, mean parity $2.8 \pm 1.3$ and mean duration of pregnancy was 37 Weeks Amenorrhea (WA). Evacuation from other facilities was the main mode of admission $(91.8 \%, n=112)$ and blood transfusion was the essence of resuscitation. Complications were observed in $80.3 \%(n=98)$. During the study, 118 maternal deaths were reported of which $15.6 \%(n=19)$ related to SAPH. Among SAPH cases who died $(n=19)$ majority $(n=16)$ had severe anemia $(n=16 ; 82.6 \%, p=0.004)$. Ten women (8.19\%) were admitted in Intensive Care Unit (ICU). Fifteen premature births (12.3\%) and 22 perinatal deaths (18.1\%) were recorded. Evacuation $(p=0.04)$, critical clinical condition during admission ( $p=0.004)$, and Uterine Rupture (UR) $(p=0.002)$ were associated with poor outcome. The Retroplacental Hemorrhage (RPH) (40.9\%) was the most common cause of fetal death $(p=0.005)$ and was associated with High Blood Pressure (HBP) and pre-eclampsia.
\end{abstract}

Conclusion: APH is a complication associated with significant maternal and fetal morbidity and mortality.

Keywords: Severe antepartum hemorrhage, Third trimester, Pregnancy

\footnotetext{
* Correspondence: m.hamtaani@gmail.com

${ }^{1}$ Resident Anesthesia and Resuscitation, Yalgado Ouedraogo Hospital, 15 BP

106 Ouagadougou 15, Burkina Faso

Full list of author information is available at the end of the article
} International License (http://creativecommons.org/licenses/by/4.0/), which permits unrestricted use, distribution, and reproduction in any medium, provided you give appropriate credit to the original author(s) and the source, provide a link to the Creative Commons license, and indicate if changes were made. The Creative Commons Public Domain Dedication waiver (http://creativecommons.org/publicdomain/zero/1.0/) applies to the data made available in this article, unless otherwise stated. 


\section{Background}

Worldwide approximately 830 women die every day from preventable causes related to pregnancy and childbirth; $99 \%$ of those 830 daily deaths are women from developing countries. [1] Direct obstetrical complications are the main causes of maternal deaths, with bleeding [2] identified as the first cause. In Burkina Faso maternal mortality remains high, with 2,700 deaths per 100,000 deliveries [1]. Hemorrhage is the leading cause of maternal mortality globally, accounting for approximately $27 \%$ of deaths worldwide; this includes postpartum, intrapartum and antepartum hemorrhage [3]. In developed countries, hemorrhage prior to delivery accounts for only $16.3 \%$ of maternal deaths, while Sub-Saharan Africa remains high at $24.5 \%$. Antepartum Hemorrhage (APH) is defined as bleeding from the vagina after 24 weeks [4]. In France [5] Serious Obstetrical Hemorrhage (SOH) represented $19 \%$ of admissions to the Intensive Care Unit (ICU). Worldwide postpartum hemorrhage (PPH) has been well studied, but APH and intrapartum hemorrhage (IPH) are less well-documented. APH is an obstetric emergency significantly contributing to perinatal and maternal morbidity and mortality. PPH yields mainly maternal complications and may be in itself a complication of APH. However, during APH, complications can be fetal as well as maternal. The maternal complications are malpresentation, premature labor, $\mathrm{PPH}$, sepsis, shock and retained placenta [6]. Various fetal complications are prematurity, low birth weight, intrauterine death, congenital malformation and birth asphyxia [7].

The obstetric department of Ouagadougou is the main and sole national reference center. Patients are generally referred from health facilities at least $150 \mathrm{~km}$ from Ouagadougou. The obstetric department has 81 beds plus 9 intensive care beds. It is poorly equipped in material, and drug supply is scarce. Specialized personnel consist of 13 obstetricians, 17 nurses specialized in anesthesia, 38 midwifes, and one anesthesiologist. Our study aims to evaluate the incidence and outcome of severe $\mathrm{APH}$ in the third trimester of pregnancy prior to delivery in Yalgado Ouedraogo Hospital in Burkina Faso.

\section{Methods}

This was an analytical cross-sectional study with prospective collection of data during 12 consecutive months $\left(1^{\text {st }}\right.$ of February 2012 to $31^{\text {st }}$ of January 2013). Informed written consent was obtained from each participant or her guardian, and confidentiality was assured. Patients who refused to participate were thanked without any further pressure to change or explain their refusal. The study included women admitted in the obstetric service during their third trimester of pregnancy with hemorrhage. To qualify as "Severe AntePartum Hemorrhage" in this study, the hemorrhage had to satisfy at least one of the following criteria: a blood loss above $2000 \mathrm{ml}$, a loss of $150 \mathrm{ml} / \mathrm{min}$, a loss of $50 \%$ of blood volume within $3 \mathrm{~h}$, a decrease of maternal hemoglobin concentration of $4 \mathrm{~g} / \mathrm{dl}$, transfusion needs greater than 4 units, [8] maternal hemoglobin concentration less than $6 \mathrm{~g} / \mathrm{dl}$ at any point of time, bleeding with vital signs instability (maternal pulse less than 50 or higher than $100 \mathrm{bpm}$, systolic blood pressure less than $100 \mathrm{mmHg}$ and diastolic pressure $\leq 50 \mathrm{mmHg}$ ) or hemorrhagic shock. In our study, serious obstetrical hemorrhage is specifically referring to $\mathrm{APH}$ and IPH in the $3^{\text {rd }}$ trimester. Patients who met at least one of these criteria were included. Our center already published its results about $\mathrm{PPH}$, which results are therefore not included in the present study. Data collection was based on the clinical review, interview, admission register and ultrasound archives. Causes of hemorrhage were diagnosed by ultrasound, clinical assessment or intra-operative findings. Socio-demographic data, causes for hemorrhage, case management, maternal and fetal outcomes were reviewed and analyzed. Delay to transfusion was defined as the time elapsed from the decision to transfuse to actual blood transfusion. Definitions: A transfer is the referral of a patient from another service in the same hospital. A reference is the non-emergency transfer of a patient from a health facility to another high performance facility. An evacuation is an emergency referral of a patient from a health facility to another high performance facility. Data were analyzed with EPI Info 3.5 and results expressed as a mean for quantitative values, median, extremes and a percentage for qualitative values. Association between variables was investigated by the Chi 2 test, and a p value less than 0.05 was considered as statistically significant. The present study was approved by National Center of Scientific Reseach and Technologic (NCSRT) committee of Burkina Faso. Strict confidentiality was ensured for all personal data.

\section{Results}

During our study, 7,469 women were admitted in obstetrics. Among them, 3,645 women experienced a hemorrhage, and from that group again 122 (1.6\%) women experienced SAPH. Seventy-nine patients live inside Ouagadougou. Demographic, obstetrical and clinical data are illustrated in Tables 1 and 2 below. Table 2 focuses on clinical data and the causes of hemorrhage.

In our study, 112 (91.8\%) patients were evacuated. From that total, 63 patients $(56.3 \%)$ were from inside the capital city of Ouagadougou and 49 patients $(43,7 \%)$ were from outside Ouagadougou. During evacuation, $65 \%$ of all women evacuated were accompanied by a nurse, none by a doctor. Women coming from outside Ouagadougou (35.2\%) were assisted by nurse only (18\%) and others came by themselves (4.5\%). Retroplacental hematomas occurred much more frequently in patients with high blood pressure (HBP) history $(75 \%, n=12 / 16 ; p=0,004)$ or pre-eclampsia 
Table 1 Demographic and obstetrical data

\begin{tabular}{|c|c|c|c|}
\hline Data & Mean \pm a [95\%] & Number $\mathrm{n}$ & Frequency $\%$ \\
\hline Age (years) & $27.8 \pm 6.9[16-45]$ & & \\
\hline Parity & $2.8 \pm 1.3[0-8]$ & & \\
\hline \multicolumn{4}{|l|}{ Job } \\
\hline Housewife & & 82 & 67.2 \\
\hline Official & & 9 & 7.4 \\
\hline Informal sector & & 12 & 9.8 \\
\hline Scholar/Student & & 19 & 15.6 \\
\hline \multicolumn{4}{|l|}{ Mode of admission } \\
\hline $\begin{array}{l}\text { Referral from others } \\
\text { facilities }\end{array}$ & & 112 & 91.8 \\
\hline Direct admission & & 9 & 7.4 \\
\hline Already hospitalized & & 1 & 0.8 \\
\hline Age of pregnancy & 37 WA [28-41] & & \\
\hline$\geq 3$ Prenatal Consults & & 92 & 75 \\
\hline $\begin{array}{l}\text { Pregnancy-related } \\
\text { morbidity }\end{array}$ & & 98 & 80.3 \\
\hline Hemorrhage & & 22 & 22.5 \\
\hline Anemia & & 89 & 90.8 \\
\hline Systemic Hypertension & & 16 & 16.3 \\
\hline Pre-eclampsia & & 27 & 22.13 \\
\hline History of Cesarian section & & 7 & 5.7 \\
\hline
\end{tabular}

WA Weeks of amenorrhea
Table 2 Clinical and biological data $(n=122)$

\begin{tabular}{|c|c|c|c|}
\hline Data & $\begin{array}{l}\text { Mean } \pm a \\
{[95 \%]}\end{array}$ & Number $\mathrm{n}$ & Percentage \% \\
\hline \multicolumn{4}{|l|}{ Admission diagnosis } \\
\hline Hemorrhage & & 78 & 63.9 \\
\hline Pelvic pain & & 12 & 9.8 \\
\hline Anemia & & 28 & 23,0 \\
\hline Coma & & 4 & 3,3 \\
\hline \multicolumn{4}{|l|}{ Condition during admission } \\
\hline Critical condition & & 48 & 39.4 \\
\hline Stable condition & & 74 & 60.6 \\
\hline $\begin{array}{l}\text { Hb prior to transfusion } \\
\text { order }\end{array}$ & $6.8 \mathrm{~g} / \mathrm{dl} \pm 1,2$ & & \\
\hline$\leq 6 \mathrm{~g} / \mathrm{dl}$ & & 101 & 82.8 \\
\hline $6-9 \mathrm{~g} / \mathrm{dl}$ & & 16 & 13.1 \\
\hline $9-11 \mathrm{~g} / \mathrm{dl}$ & & 5 & 4.1 \\
\hline \multicolumn{4}{|l|}{ Classification } \\
\hline Antepartum & & 78 & 63.9 \\
\hline Intra partum & & 44 & 36.1 \\
\hline \multicolumn{4}{|l|}{ Causes of hemorrhage } \\
\hline Placenta Prævia & & 52 & 42.6 \\
\hline Retro Placental Hematoma & & 40 & 32.8 \\
\hline Uterine Rupture & & 30 & 24.6 \\
\hline
\end{tabular}

$\mathrm{Hb}$ Hemoglobin concentration

Cesarean delivery $(n=9 ; 9.1 \% ; p=0.1)$. Obstetrical management is described in Fig. 1. No patient benefited from interventional radiology because of its unavailability in Burkina Faso. Ten patients (8.19\%) were admitted in the Intensive Care Unit (ICU) where six of them died. Resuscitation consisted of oxygen therapy, intravenous fluids administration, transfusion, vasoactive drugs (5 cases), antibiotics, intubation and mechanical ventilation (3 cases). Complications occurred for $80.3 \%(n=98)$ of patients including worsening anemia (90 cases, 73.7\%), severe sepsis $(n=26 ; 21.3 \%)$ and hemostatic disorders $(n=4$, 3.2\%). Table 4 below describe maternal and fetal outcomes.

Our study showed SAPH mortality rate was $16.1 \%$. The average age of deceased patients was 27.2 years and the majority of them were evacuated. Reference $(p=$ $0,001)$ and not transfusion $(p=0,002)$ were risks factors associated with maternal mortality. Patients died because of multiple organ failures in eight cases, and coagulopathy $(n=6)$ or lack of blood products. Preterm delivery occurred in $12.3 \%(n=15)$. Twenty-two perinatal deaths $(18.1 \% ; n=22)$ were recorded, including 12 apparent stillborn and 10 macerated stillborn. Retro placental hematoma was associated with a $25 \%$ fetal mortality rate ( $n=10 / 40$ cases), significantly higher than placenta praevia $(n=7$ cases on $52,13.5 \%)$ and uterine rupture $(n=6 / 30,20 \%)(p=0.005)$ as indicated in Table 4 below. 


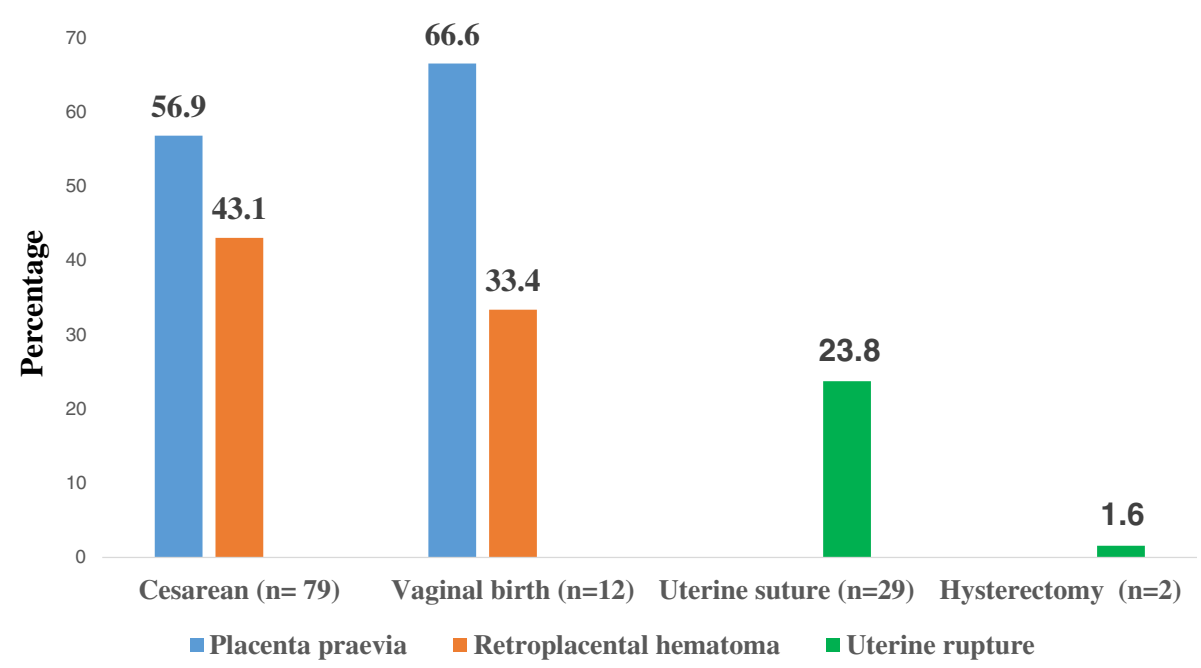

Fig. 1 Obstetrical management data $(n=122)$. The Figure 1 describe the obstetrical management of serious ante partum hemorrhage according type of pathology. There are three types of diseases as placenta previa, retroplacental hematoma uterine rupture. These diseases are managed by cesearan section mainly $(n=110)$ againts vaginaly birth in 12 cases. Among cesearan cases, uterine suture was performed in 29 cases against hysterectomy in two cases

\section{Discussion}

SAPH are not very frequent in our study (1.6\%). Such low frequency also was reported by Takpara [9] et al. (5.5\%) in Benin. In comparison to nearly $5 \%$ of pregnancies [10] in France. In our study, 78 patients had ante partum hemorrhage $(63.9 \%)$ against 44 cases $(33.1 \%)$ for intra partum hemorrhage. According to a World Health Organization (WHO) study in Sub-Saharan Africa, APH accounts for $8.4 \%$ of all maternal hemorrhage versus $0.9 \%$ for $\mathrm{IPH}^{3}$. SAPH is more frequent in developing countries than in developed countries $[3,11]$ In fact, data must be analyzed cautiously; our study is limited to severe hemorrhage while most publications concern all types of hemorrhage.

The average age of our patients was 27.8 years. In Burkina Faso, half of women marry before 17.5 years old, and the majority of women give birth to their first child before 20 years old [12]. This young age is reported by other authors, [13, 14] Women living outside Ouagadougou represented $35.2 \%$ of total patient our study. These patients were referred which contributed to a delay in decision making and increased maternal morbidity and mortality. During admission, severe clinical anemia $(\leq 6 \mathrm{~g} / \mathrm{dl})$ was observed in 101 patients $(82.8 \%)$.

The majority of women were referred form other facilities (91.8\%). Pregnancies had been relatively well attended with 3 antenatal consultations for $65 \%$ of them. Burkina Faso has a pyramidal organization of health care facilities. The obstetric department of Ouagadougou is the main and only national reference center. Patients are generally referred from health care facilities located more than $150 \mathrm{~km}$ from Ouagadougou. In our study, $112(91.8 \%)$ patients were referred. During reference, $65 \%$ of all women referred were accompanied by a nurse, none by a doctor. Women coming outside Ouagadougou $(43,7 \%)$ were assisted by nurse only (18\%) and others came themselves (4.5\%). Ouattara and al [15] reported that the reference process accounted for $43 \%$ of admissions in the same service where we conducted our study. The insufficiency of heath service and poorly maintained or low availability of equipment are some of explanations of this situation. Women were relatively followed up during pregnancy in our study like some other study [12].

There was a delay in the management of pregnant patients' bleeding and patients were often previously anemic. Rhesus blood grouping and hemoglobin measurement were performed in emergency as described in the literature $[9,16]$ Given the excellent results of ultrasound examination, any suspicion of obstetric pathology justifies its use, but because of unavailability, it was performed only for 6 patients (5\%), identifying 4 cases of Placental Previa (PP) and 2 cases of Retroplacental hematoma $(\mathrm{RPH})$ in our study. The main causes of SAPH are PP, followed by RPH and Uterine Rupture (UR). These three pathologies are common in Africa [9, 14] The PP incidence accounted for $41.80 \%$ of severe APH $(n=51)$ in our series. In the literature, abnormal placental insertions were responsible of 5 to $10 \%$ of SAPH $[10,17]$ In our study, RPH caused 32.8\% $(n=40)$ of SAPH. Takpara et al. [9] in Benin reported that RPH was responsible of $5.8 \%$ of serious obstetrical hemorrhage. RPH occurred in $0.5 \%$ of all pregnancies, and complicate 0.2 to $0.4 \%$ of these pregnancies with a perinatal mortality about $20.2 \%$ related to hemorrhage $[17,18]$ Obstetric hemorrhage was due to UR in $42 \%(n=31)$ in our study from which 2 cases $(6.5 \%)$ occurred on a scarred uterus and other $3 / 4$ on healthy uterus. 
Table 4 Maternal and fetal outcomes $(n=122)$

\begin{tabular}{|c|c|c|c|c|c|}
\hline Variables & Mean & $\begin{array}{l}\text { Number } \\
\mathrm{n}\end{array}$ & $\begin{array}{l}\text { Mortality } \\
\mathrm{n}\end{array}$ & $\begin{array}{l}\text { Mortality } \\
\%\end{array}$ & $p$ \\
\hline \multicolumn{6}{|l|}{ Admission } \\
\hline External transfer & & 112 & 19 & 16.9 & 0.004 \\
\hline Self-consultation & & 9 & 0 & & \\
\hline Internal Referral & & 1 & 0 & & \\
\hline \multicolumn{6}{|l|}{ Clinical status } \\
\hline Critical & & 48 & 12 & 25 & 0.002 \\
\hline Stable & & 74 & 7 & 5.7 & \\
\hline Age (years) & 27.2 & & & & 0.3 \\
\hline [16-20] & & 25 & 6 & 24 & \\
\hline$[21-25]$ & & 31 & 4 & 12.9 & \\
\hline [26-30] & & 30 & 2 & 6.7 & \\
\hline [31-35] & & 21 & 5 & 23.8 & \\
\hline [36-40] & & 14 & 2 & 14.3 & \\
\hline$[41-45]$ & & 1 & 0 & 0 & \\
\hline All & & 122 & 19 & 15,6 & \\
\hline \multicolumn{6}{|l|}{ Etiology } \\
\hline $\begin{array}{l}\text { Retroplacental } \\
\text { hematoma }\end{array}$ & & 40 & 7 & 17.5 & 0.04 \\
\hline Placenta Previa & & 51 & 3 & 5.8 & \\
\hline Uterine Rupture & & 31 & 9 & 29 & 0.002 \\
\hline \multicolumn{6}{|l|}{ Maternal outcome } \\
\hline ICU and transfused & & 10 & 10 & 100 & 0.3 \\
\hline Transfused in obstetric & & 93 & 4 & 4.3 & 0.56 \\
\hline Not transfused & & 9 & 5 & 55.55 & 0,001 \\
\hline Evacuated & & 112 & 16 & 14,3 & 0,003 \\
\hline Not evacuated & & 10 & 3 & 30 & 0,08 \\
\hline Cesarean delivery & & 110 & 10 & 9,1 & 0,1 \\
\hline Vaginal delivery & & 12 & 9 & 75 & 0,004 \\
\hline \multicolumn{6}{|l|}{ Fetal outcome } \\
\hline Evacuated & & 112 & 21 & 18,7 & 0,0001 \\
\hline Not evacuated & & 10 & 1 & 10 & 0,07 \\
\hline \multicolumn{6}{|l|}{ Cesarean delivery } \\
\hline Placenta Previa & & 45 & 2 & 4.44 & 0.01 \\
\hline $\begin{array}{l}\text { Retroplacental } \\
\text { hematoma }\end{array}$ & & 34 & 5 & 14.28 & 0.005 \\
\hline Uterine Rupture & & 30 & 6 & 20 & 0,03 \\
\hline \multicolumn{6}{|l|}{ Vaginal birth } \\
\hline Placenta Previa & & 8 & 5 & 62.5 & 0.01 \\
\hline $\begin{array}{l}\text { Retroplacental } \\
\text { hematoma }\end{array}$ & & 4 & 4 & 100 & 0.003 \\
\hline Uterine Rupture & & - & - & - & - \\
\hline
\end{tabular}

In our study, the high proportion of UR on healthy uterus may be related to multiparty, lack of support for pregnancy, fetal and pelvic disproportion, unfavorable socio-economic status, prolonged labor, and delayed consultation.

SAPH was responsible of $8.2 \%$ of intensive care unit admissions in our study. All cases of SAPH must be admitted in intensive care, but the lack of health insurance is an obstacle to their admission unlike in others countries [5, 18, 19] Despite the availability of Emergency Obstetric and Neonatal Care (EmONC), there was no protocol for hemorrhage management in this service. Measures such as the left lateral position, oxygen supplement were effective for 77 patients (63.4\%). Volume expansion with saline $(n=122)$ and gelofusin $(n=88 ; 72 \%)$ were implemented. Thirteen percent $(n=16)$ of women did not receive oxygen due to lack of supplies (oxygen mask, nasal prongs). Like in others' Africans studies, maternal resuscitation was hampered by the lack of blood products [20]. In our studied population, uncovered transfusion needs were reported for 18 patients (14.8\%), but no patient needed massive transfusion. The average waiting time for transfusion was long $(3.8 \mathrm{~h})$ and Bonkoungou [21] in the same service reported $5.2 \mathrm{~h}$ delay to transfusion. In our series, one of the ten women died because of the lack of blood products. The transfusion products were mainly erythrocytes. Two patients received fresh frozen plasma for clotting disorders. There are no publications on stock-outs of supplies and blood in this Hospital and data are unavailable. A further research information is needed to establish the no covered rate of blood transfusion. Oxytocin and antibiotics were used in our study like in others studies [9].

A Cesarean section was performed for 79 patients (64.8\%). This rates are similar to Beninese data [9]. Eight woman who gave birth vaginally could have been cared in a peripheral clinic and this raises questions about the qualification of agents that referred women. A hysterectomy was performed in 2 cases $(1.6 \%)$ after failure of conservative treatment. In the study of Nayama et al. [22] in Niger 18,934 deliveries had been registered from which 154 patients had benefited from obstetric hysterectomy $(0.8 \%)$. Despite this radical rescue surgery, a patient died in post-operative period. The decision to perform a hysterectomy remains difficult, especially in the African socio-cultural context [13] and among young women. The delay in management explains the high mortality reported both in our study and in the Takpara [9] study.

The major morbidity was anemia $(73.4 \%)$ in our study as described in the literature [14]. Anemia is often part of the continuum of pregnancy. The second cause of morbidity was infection. Maternal death rate in our study was $15.6 \%$. Hemorrhage is responsible for $27,1 \%$ of maternal deaths according to Say and al [3]. The mortality rate in our series is comparable to what Cissé [23] reported $(16.4 \%)$. UR was the deadliest $(29 \%)(p=0.06)$ in 
our study. According to literature RPH caused 7 to $20 \%$ of maternal deaths related to hemorrhage during the third trimester of pregnancy $[17,18]$. The need of patients to be referred $(p=0.04)$, critical condition during admission $(p=0.004)$, and uterine rupture $(p=0.002)$ were poor outcome factors in our study. In Africa, the insufficiency of equipment, drugs for resuscitation and delay to health care utilization increase the mortality rate. So delay can be attributed to poor access to supplies and to blood products. Despite resuscitation and Cesarean section practice, fetal outcome remained severe. Fifteen premature births (12.3\%) and 22 perinatal deaths $(18.1 \%)$ were recorded in our study. This rate of stillbirths was comparable to Takpara [9] data (14.7\%). $\mathrm{RPH}$ remained the most feticide (27.3\%) in our study. According to Mercier and al [24] RPH was responsible of $20.2 \%$ perinatal mortality. During pregnancy, high blood pressure, pre-eclampsia must be researched and managed in order to reduce risk of placenta abruption.

\section{Conclusion}

APH is serious obstetric complication. Young women were concerned. $\mathrm{SOH}$ is associated with significant maternal and fetal morbidity and mortality. It is a frequent reason for consultation, and its outcome can be fatal without early and appropriate management. The lack of blood products, insufficient equipment, poor medical condition upon transfer from health facilities, and delayed resuscitation each impacted the effectiveness of the APH management. Since April 2016 with the establish 43,7\%) ent of general health insurance for obstetric and pediatric care in our country, we hope that pregnancy will have more attention and good care. However, some effort must be done to improve availability of skilled resources.

\section{Abbreviations \\ EmONC: Emergency obstetric and neonatal care; HBP: High blood pressure; ICU: Intensive care unit; IPH: Intra partum hemorrhage; PC: Prenatal consultation; PP: Placenta previa; PPH: Postpartum hemorrhage; RPH: Retroplacental hematoma; SAPH: Severe antepartum hemorrhage; UR: Uterine rupture; WA: Weeks of amenorrhea}

\section{Acknowledgments}

We gratefully acknowledge Professor Francis Veyckmans who revised it critically for important or intellectual content. Particular mention to Professor Philippe Baele from Belgium who carefully made critical analysis and improved the English language.

\section{Funding}

This study was not funded.

\section{Availability of data and materials}

The datasets used and/or analysed during the current study are available from the corresponding author. LANKOANDE Martin, m.hamtaani@gmail.com; 15 BP 106 Ouagadugou 15, Burkina Faso.

\section{Authors' contributions}

All authors listed on the manuscript have made substantial contributions to the conception and design of the study. PB made contributions to the study design and protocol. DM made data collection and analyses plans. ML collected data at the sites and drafted the article; all other authors revised it critically for important or intellectual content, and approved the final version.

Competing interests

All authors declare that they have no competing interests.

Consent for publication

not applicable.

Ethics approval and consent to participate

The present study was approved by the National Center of Scientific Research and Technologic Committee (NCSRTC) of Burkina Faso.

\section{Publisher's Note}

Springer Nature remains neutral with regard to jurisdictional claims in published maps and institutional affiliations.

\section{Author details}

${ }^{1}$ Resident Anesthesia and Resuscitation, Yalgado Ouedraogo Hospital, 15 BP 106 Ouagadougou 15, Burkina Faso. ${ }^{2}$ Yalgado Ouédraogo Hospital, Ouagadougou, Burkina Faso. ${ }^{3}$ Blaise Compaore Hospital, Ouagadougou, Burkina Faso. ${ }^{4}$ Cliniques University Saint Luc, Woluwe-Saint-Lambert, Belgium.

Received: 11 June 2016 Accepted: 14 May 2017

Published online: 31 May 2017

References

1. WHO, UNICEF, UNFPA, World Bank Group and the United Nations Population Division. Trends in maternal mortality: 1990 to 2015. Fact sheet N³48, WHO/RHR/15.23:2015; 12. http://apps.who.int/iris/bitstream/10665/ 194254/1/9789241565141_eng.pdf?ua=1.

2. Magnin G. Hémorragies du troisième trimestre de la grossesse. Rev Pratic. 1997:47:1470-1.

3. Say L, Chou D, Gemmill A, Tunçalp Ö, Moller AB, Jane D, Gülmezoglu AM, Temmerman M, Alkema L. Global causes of maternal death: a WHO systematic analysis. Lancet Glob Health. 2014;2:e323-33.

4. Wasnik SK, Naiknaware SV. Antepartum hemorrhage: causes \& its effects on mother and child: an evaluation. Obstet Gynecol Int J. 2015;3(1):00072. doi: 10.15406/ogij.2015.03.00072.

5. Koeberlé P, Lévy A, Surcin S, Bartholin F, Clément G, Bachour K, Boillot A, Capellier G, Riethmuller D. Complications obstétricales graves nécessitant une hospitalisation en réanimation : étude rétrospective sur 10 ans au $\mathrm{CHU}$ de Besançon. Ann Fr Anesth Reanim. 2000;19:445-51.

6. Kedar K, Uikey P, Pawar A, Choudhary A. Maternal and fetal outcome in antepartum haemorrhage: a study at tertiary care hospital. Int J Reprod Contracept Obstet Gynecol. 2016;5:1386-93.

7. Cunningham F, Leveno K, Bloom S, Hauth J, Gilstrap L, Rouse D, et al. Obstetrical haemorrhage. Williams obstetrics. 23rd ed. New York: McGraw Hill Professionals; 2009. p. 2-3.

8. Anderson E. Major obstetric haemorrhage - Clinical guideline for management. 6th ed. Truro: Royal Cornwall Hospitals NHS Trust, Human Resources Department, Knowledge Spa; 2014

9. Takpara I, Coco B, Cholbli M, Alhionou E. Prise en charge des hémorragies graves en obstétriques à la Clinique universitaire de gynécologie et d'obstétrique du CHNU de Cotonou. Bénin Médical N¹0 1998; 23-29.

10. Levy G, Dailland P. Hémorragies en obstétrique. Encycl Méd Chir (Elsevier, Paris), Anesthésie-Réanimation 36-820-A-10. 1998:16

11. Purohit A, Desai R, Jodha BS, Babulal G. Maternal and fetal outcome in third trimesters bleeding. IOSR J Dent Med Sci. 2014:5(3):13-1.

12. Langer J, Berger C, Magnin G. Diagnostic et conduite à tenir devant une

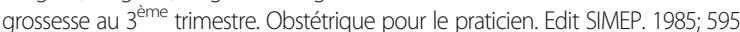

13. Ba MG, Faye EO, Kpekpede F, Dravé A. Morbidité maternelle et modalités thérapeutiques dans la prise en charge. Med Trop. 2002:304-308

14. Admassu A. Analysis of ruptured in Debre Markos Hospital. Ethiopia in 2004. East Afr Med J. 2004;81(1):52-5.

15. Ouattara A, Ouedraogo CM, Ouedraogo A, Lankoande J. Obstetric emergency and non-emergency transfers to the university teaching hospital Yalgado ouedraogo of Ouagadougou : a 3-year study of theirNepidemiologic, clinical, and prognostic aspects. Med Sante Trop. 2015;25:403-7.

16. Adriamady R C. Mortalité maternelle à la Clinique de Befelatanana. Jr. Gynécol Obst Biol Reprod. 2000;29(5):501 
17. Karegard M, Gennser $\mathrm{G}$. incidence and recurrence rate of abruption placentae in Sweden. Obstet Gynecol. 1986;67:523-8.

18. Ducloy-Bouthors A-S, E. Jessenne, B. Dedet, P. Deruelle, A. Tournoys, J. Sicot. Hémorragies du troisième trimestre. 51e Congrès national d'anesthésie et de réanimation. Médecins. Urgences vitales. @ 2009;1-15.

19. Amelia Banks, Andrew Norris. Massive haemorrhage in pregnancy. Continuing Education in Anaesthesia, Critical Care \& Pain 2005;| 5 n 6:195-198

20. Diallo FB. IDI N. La rupture utérine à la maternité centrale de référence de Niamey. Med d'Afr Noire : Médecine d'Afrique Noire. 1998;45 (5):310-315

21. Bonkoungou P, Lankoandé M, Kinda B, Simporé A, Kaboré Raf, Sanou J, Thiéba B., Ouedraogo Nazinigouba. Indications de la transfusion et pronostic des femmes transfusées au Département de Gynécologie Obstétrique du CHU Yalgado Ouédraogo de Ouagadougou. Rev Afr Anesth Réa Med Urg. 2014. Tome 19 N²;1-4

22. Nayama N, Gama-Alio A, Garba A, Idi N, Oumara M, Guede S, et al. Hystérectomies obstétricales à la maternité Issaka Gzoby de Niamey. Med Afr Noire. 2007;61(12):289-95.

23. Cisse $C T$, Faye EO, De Bernis L, Diadhiou F. Rupture utérine au Sénégal : épidémiologie et qualité de la prise en charge. Med Trop. 2002;62:619-22.

24. Mercier FJ, Van de Velde M. Major obstetric hemorrhage. Anesthesiol Clin. 2008;26:53-66.

\section{Submit your next manuscript to BioMed Central and we will help you at every step:}

- We accept pre-submission inquiries

- Our selector tool helps you to find the most relevant journal

- We provide round the clock customer support

- Convenient online submission

- Thorough peer review

- Inclusion in PubMed and all major indexing services

- Maximum visibility for your research

Submit your manuscript at www.biomedcentral.com/submit 